\title{
The Proportionality of Women Graduated from the Professional Career of Mechanical and Electrical Engineering at UNTELS: Analysis of their Academic Performance and Labor Field of Action
}

\author{
Dora Yvonne Arce Santillan ${ }^{1, *}$, Omar Freddy Chamorro Atalaya ${ }^{1}$, Yesica Pamela Leandro Chacón ${ }^{1}$, Jorge Isaac Castro Bedriñana ${ }^{2}$, \\ Elizabeth Rosario Martínez Santillán ${ }^{3}$
}

${ }^{1}$ Faculty of Engineering and Management, Universidad Nacional Tecnológica de Lima Sur Lima, Lima, Perú

${ }^{2}$ Faculty of Zootechnics, Universidad Nacional del Centro del Perú, Huancayo, Perú

${ }^{3}$ Faculty of Medical Technology, Universidad Nacional Federico Villareal, Lima, Perú

\begin{tabular}{l} 
A R T I C L E I N F O \\
\hline Article history: \\
Received: 20 November, 20 \\
Accepted: 28 January, 2020 \\
Online: 07 February, 2020 \\
\hline Keywords: \\
Academic performance \\
Graduated Women \\
Mechanical and Electrical \\
Engineering \\
Development Field \\
Mechanics Subjects \\
Electrical subjects
\end{tabular}

\section{Introduction}

Women represent 52 percent of the world's population, but do not appear to be included in the careers of science, technology, engineering and mathematics, remaining as a mostly male reducer; starring less than $20 \%$ of university enrollments, however the historical trend has been reversing and increasing female participation, especially in some specialties of engineering.

In recent years, there has been an increase in the professional development of women in engineering careers. This is because

* Dora Yvonne Arce Santillan; Sector 3 Grupo 1A 03, Av Central, Villa El Salvador - UNTELS. doratella_92@hotmail.com www.astesj.com

https://dx.doi.org/10.25046/aj050147

\begin{abstract}
A B S T R A C T
This research seeks to describe the proportionality of women graduated from the efsional Career of Mechanical and Electrical Engineering, analyzing their academic performance and the field of work action in which they are working. This study was done continue purpose of highlighting academic performance, and encouraging women to is not for women; In addition, this study will be a source of information for the National Technological University of Lima Sur, since, with this, action plans can be generated to increase the number of women entering in the coming years. Once the research has been carried out, it is concluded that the percentage of women who graduate in relation to the percentage of men, per academic semester 2012-II to 2018-II, is equal to $8.1 \%$. Likewise, the weighted average of the academic performance of women graduated in the professional career of Mechanical and Electrical Engineering, is 12.98, this represents a high average for the career; so it can be indicated that the 38 women graduated, have had a good academic performance. Finally, it is concluded that there is a high Spearman ratio of 0.822 between the weighted average by specialty with the field of labor action; These results agree with what has been indicated in relation to the fact that there is a higher qualification in the specialty of Mechanics (AM) with a weighted average range of subjects from 11.73 to 15.42 , and according to professional practice reports, of the 38 women graduated from the Mechanical and Electrical Engineering career, 25 are working in the field of Mechanical cialty. With these results it can be said that although the percentage of women linked to this career is still low; Women in Mechanical and Electrical Engineering have a good academic development, which is why women should continue to be encouraged to be included in the area of science, technology and innovation.
\end{abstract}

little by little, myths and beliefs about the position that women have in society have been left behind. [1] Although this insertion in this sector has been difficult for women, they have been placed in different areas where their potential can be exploited.

Women participate as men in the fields of training and especially in the university, but the distribution by career of both sexes is very different. Women opt for careers related to the humanities, education or health sciences to a greater extent. The careers that are within the range of "hard", such as engineering, remain poorly chosen by women, remaining as a mostly male stronghold. [2] 


\section{Arce et al. / Advances in Science, Technology and Engineering Systems Journal Vol. 5, No. 1, $368-372$ (2020)}

Thus, far from being able to say that the low percentage of women who decide on engineering careers is something the result of the late incorporation of women into the university, and the world of work in general, and that it will increase as normalized The situation of equality in society, the number of women who opt for engineering continues to decline, regardless of whether women are achieving effective equality in all other aspects of society. [3]

However, it is also recognized that female participation in higher education in Latin America follows in general terms, a pattern that favors some areas of knowledge over others. [4] However, it should be noted that while female participation in areas such as industrial engineering and computer engineering increases, other areas such as mechanical engineering and electrical engineering are still considered as low or nil preference of women.

It is probably because of this, that the work of women is strongly related to the secondary, "supportive" of men, undervalued and undervalued. This means for women a double challenge, on the one hand, joining the work environment and, on the other, obtaining social recognition for their professional performance. [5]

Within these implicit barriers, there are "masculine" standards associated with the scientific career that women must achieve, whether these, for cultural historical reasons, or also associated with the social division of labor. This is how for women scientists the possibility of reaching these standards, is usually, once they have finished with the vital stage of reproduction and / or upbringing, and there arises the problem that is generated by the difference in the years of trajectory. [6]

Peru is no stranger to this problem. According to the National Superintendence of University Education (SUNEDU), it indicates that, in Peru, the total undergraduate graduates in 2016 were 110,408 , of which $54.3 \%$ were women. However, the largest number of graduates are in the careers of administrative and commercial sciences and in economic and accounting sciences. Of the total graduates, only $26 \%$ were from careers linked to the CTI. Of the total CTI graduates, only $32 \%$ were women. [7]

Women are increasingly expanding their field of development related to science, technology and innovation. [8] Engineering is no stranger to them, although, the percentage of women linked to the Mechanical and Electrical Engineering Degree is still low.

A study by The National Academies of the United States has found that social stereotypes condition the academic performance of women, leading to a drop of up to $90 \%$ in studies when they are not adequately valued. [9] These prejudices cause math and engineering careers to be generally discarded by high school students, which means a loss of talent for society.

\section{Methodology}

\subsection{Kind of investigation}

This research is descriptive. [10] Initially it is intended to identify the percentage of women who graduate in relation to the percentage of men, by academic semester, it should be noted that the National Technological University of South Lima has a total of 15 promotions; In addition, the academic performance of women in the professional career of Mechanical and Electrical Engineering will be analyzed, and it will be determined if there is any type of association between the weighted average by specialty (Mechanical Subjects or Electrical Subjects) with the field of labor action where Currently, women graduated from the degree are working.

\subsection{Population and Sample}

The population of this research is represented by the 38 women graduated from the School of Mechanical and Electrical Engineering of the academic semesters 2012-II to 2018-II; It should be noted that the first promotion of graduate students of the university occurred in the academic semester 2011-II, but to date there were no women in the career. It also indicates that women represent $8.1 \%$ of the total graduates.

In that sense, the sample will be equal to the population [11]; due to the fact that the sample is less than 50, that is, the general weighted average and the weighted average by specialty (Mechanical Subjects and Electrical Subjects) of the 38 women graduated from the School of Mechanical and Electrical Engineering, until the 2018 II. Below is shown in table 1, the proportion of women and men graduated from the career of Mechanical and Electrical Engineering from 2011-II to 2018-II.

Table 1: Proportion of women and men graduated

\begin{tabular}{ccc}
\hline Graduated Men & 429 & $91.9 \%$ \\
\hline Graduated Women & 38 & $8.1 \%$ \\
Total & 467 & \\
\hline
\end{tabular}

\subsection{Measuring Instruments}

The instrument used is the technical reports [12], of the notes of the graduates of the professional school of Mechanical and Electrical Engineering; academic records, contained in the university management computer system (SIGU) of the National Technological University of South Lima, were used as a source; in the case of the field of labor development, the files are required as a source, which work in the university's degree and degree office, which requests the graduates as one of their requirements to submit reports of professional practices, in which Specify the company and the field of development.

\section{Results}

Figure 1 shows the number of women and men who graduate per academic semester, from the semester 2011-II to 2018-II.

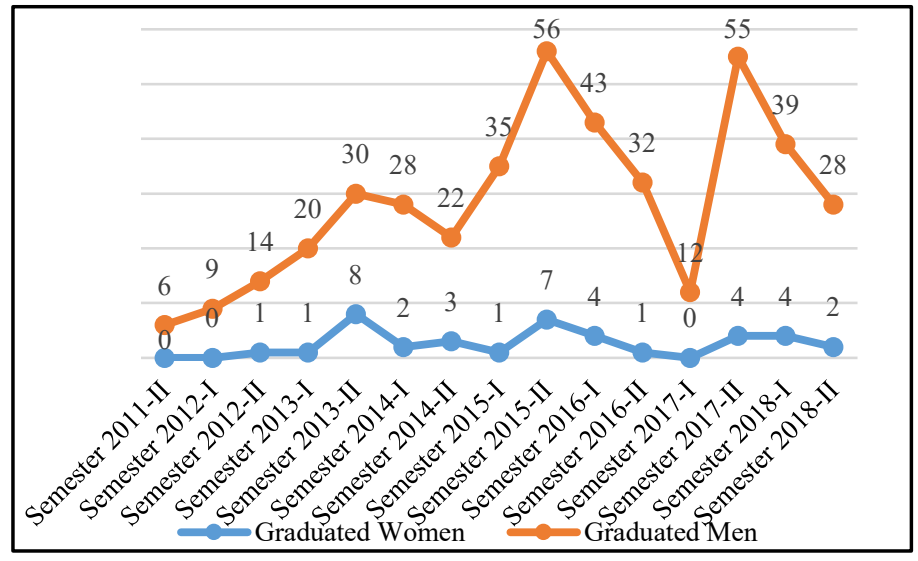

Figure 1: Proportion of women and men graduated by academic semester 


\section{Arce et al. / Advances in Science, Technology and Engineering Systems Journal Vol. 5, No. 1, 368-372 (2020)}

As shown in the previous figure, there is a greater number of men graduated in the professional career of Mechanical and Electrical Engineering, as shown in Table 1, this proportion is $8.1 \%$ of women graduated and $91.9 \%$ of men graduates

Continuing with the investigation, in the following Table 2, the subjects belonging to the areas of specialty are shown; both Electrical and Mechanical subjects.

Table 2: Subjects by specialty areas

\begin{tabular}{|c|c|c|c|}
\hline \multicolumn{2}{|c|}{ Asignaturas del Área de Mecánica } & \multicolumn{2}{|c|}{ Asignaturas del Área de Eléctrica } \\
\hline AM1 & $\begin{array}{c}\text { Industrial Manufacturing } \\
\text { Processes }\end{array}$ & AE1 & Electrical circuits \\
\hline AM2 & $\begin{array}{c}\text { Industrial Manufacturing } \\
\text { Process Laboratory }\end{array}$ & AE2 & Electrical Circuit Laboratory \\
\hline AM3 & Applied Turbomachines & AE3 & Electric machines \\
\hline AM4 & Heat Transfer & AE4 & $\begin{array}{c}\text { Laboratory of Electrical } \\
\text { Machines }\end{array}$ \\
\hline AM5 & $\begin{array}{l}\text { Welding Technology I } \\
\text { (Corrosion) }\end{array}$ & AE5 & Electrical Measurements \\
\hline AM6 & Design of machine elements & AE6 & $\begin{array}{c}\text { Electrical Measurement } \\
\text { Laboratory }\end{array}$ \\
\hline AM7 & Internal combustion engines & AE7 & Electrical installations \\
\hline AM8 & $\begin{array}{l}\text { Industrial Machines and } \\
\text { Systems }\end{array}$ & AE8 & $\begin{array}{c}\text { Control and Control Board } \\
\text { Design }\end{array}$ \\
\hline AM9 & Maintenance Engineering & AE9 & Energy Transformation \\
\hline AM10 & $\begin{array}{c}\text { Mechanical Engineering } \\
\text { Laboratory }\end{array}$ & AE10 & Renewable Energies I \\
\hline & & AE11 & Power systems \\
\hline & & AE12 & Thermoelectric plants \\
\hline & & AE13 & Lines of transmission \\
\hline & & AE14 & Electrical Protection Systems \\
\hline & & AE15 & Hydroelectric Power Stations \\
\hline
\end{tabular}

In order to determine if there is any type of association between the weighted average by specialty (Mechanical Subjects or Electrical Subjects) with the field of labor action where the 38 women graduated from the career currently work, then in Figure 2 , the weighted average of the mechanics subjects is shown, while in Figure 3 the weighted average of the electrical subjects is shown.

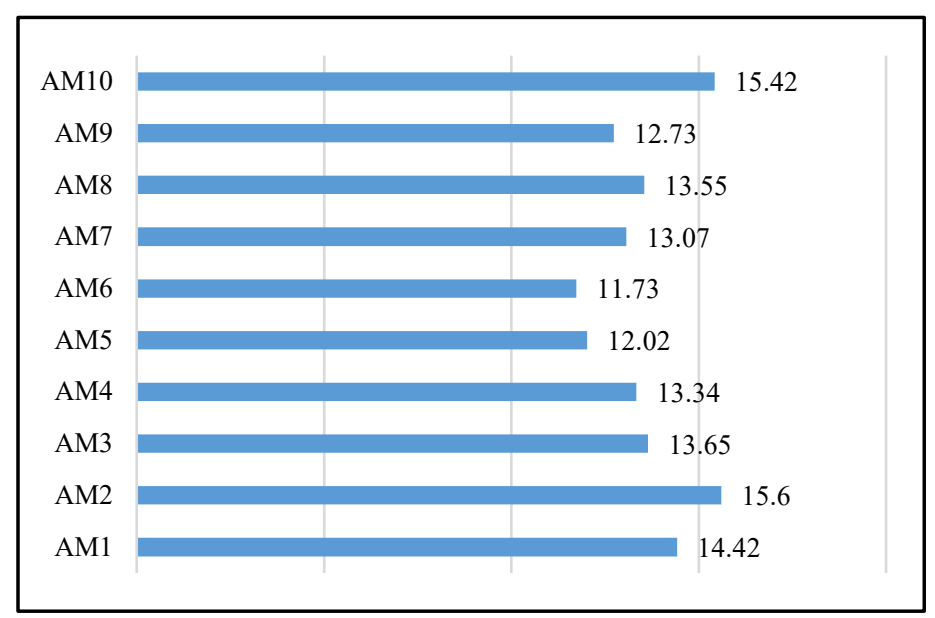

Figure 2: Weighted average of the subjects of the specialty of mechanics
As it is observed, in the previous figure the average range of the subjects of the specialty of mechanics (AM) is from 11.73 to 15.42; obtaining the highest grade the mechanical engineering laboratory subject; being this course of a practical nature, it provides the student with tests in energy transfer and transformation facilities; Likewise, the interpretation of the results of the experimental tests of the mechanical quantities is disclosed, through fundamental instruments and equipment in engineering.

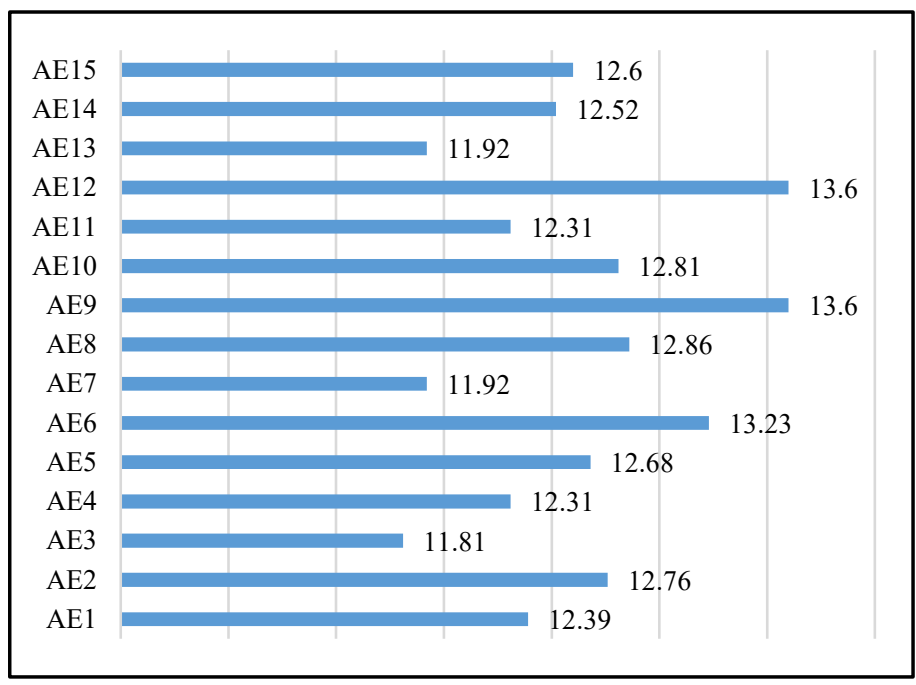

Figure 3: Weighted average of the electrical specialty subjects

As can be seen, in the previous figure, the average range of subjects in the specialty of electrical (AE) obtained by women graduates is 11.81 to 13.6 ; obtaining the highest average subjects of Thermoelectric Power Plants and Energy Transformation; being this course of a practical nature; The main objective of the course of thermoelectric plants is to show the state of the art in combustion technology for electricity generation, and the basic knowledge of economics and environment. While in the course of energy transformation it is sought to show the definitions related to the ability to work, transform or set in motion by means of the energy involved, for example in rifle fuels.

With the results obtained, it can be determined that there is a higher qualification in the specialty of Mechanics; Likewise, the general weighted average of both specialties was obtained, of the 38 women graduated, being 12.98; said average is considered high for this professional career; so it can be indicated that the 38 women graduated from the Mechanical and Electrical Engineering career have had a good academic performance.

\section{Statistical Analysis}

Next, the relationship between the weighted average by specialty (Mechanical Subjects or Electrical Subjects) with the labor field of action of the 38 graduates of the Mechanical and Electrical Engineering career will be determined; by means of the Spearman correlation test, which was carried out with the statistical program SPSS version 25. It should be noted that this test was used because the data does not have a normal distribution. [13] The following table shows the test results.

As the Spearman correlation coefficient is shown in the previous table, it is equal to -0.822 . This result can be interpreted in this way: There is a high indirect and significant relationship 
between the weighted average by specialty with the field of labor action. [14]

\begin{tabular}{|c|c|c|c|}
\hline \multicolumn{4}{|c|}{ Rho de Spearman } \\
\hline & & $\begin{array}{l}\text { Average } \\
\text { Specialty }\end{array}$ & Labor field \\
\hline \multirow{3}{*}{$\begin{array}{l}\text { Average } \\
\text { Specialty }\end{array}$} & Correlation coefficient & 1,000 &,$- 822^{* *}$ \\
\hline & Sig. (bilateral) & &, 000 \\
\hline & $\mathrm{N}$ & 38 & 38 \\
\hline \multirow{3}{*}{ Labor field } & Correlation coefficient &,$- 822^{* *}$ & 1,000 \\
\hline & Sig. (bilateral) & , 000 & \\
\hline & $\mathrm{N}$ & 38 & 38 \\
\hline
\end{tabular}

These results agree with what has been pointed out in relation to the fact that there is a higher qualification in the specialty of Mechanics and according to the reports of professional practices, of the 38 women graduated from the Mechanical and Electrical Engineering career, 25 are working in the field of Mechanics specialty. The following figure shows the percentage representation of the proportion of working in the labor field of the 38 graduates.

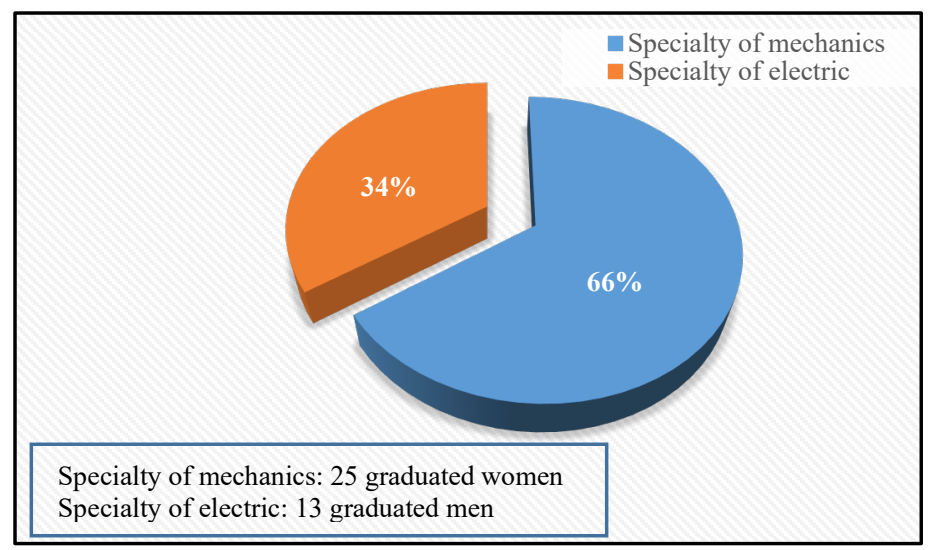

Figure 4: Percentage of the development in the field of labor action

These results agree with what has been pointed out in relation to the fact that there is a higher qualification in the specialty of Mechanics and according to the reports of professional practices, of the 38 women graduated from the Mechanical and Electrical Engineering career, 25 are working in the field of Mechanics specialty. The following figure shows the percentage representation of the proportion of working in the labor field of the 38 graduates.

The reliability criterion of the instrument was determined by Cronbach's alpha coefficient, developed by J. L. Cronbach and recommended for Likert-type attitude scales; [15] through the reliability test with the statistical program SPSS version 25 , the reliability of the instrument will be determined.

Table 4: Reliability test

\begin{tabular}{|c|c|}
\hline Cronbach Alfa & N of elements \\
\hline, 930 & 2 \\
\hline \multicolumn{2}{|r|}{ SPSS }
\end{tabular}

As can be seen, Cronbach's Alpha is equal to 0.930, so it can be affirmed that there is a "Very High Reliability and Validity of the instrument", since this value is within the range of 0.90 to 1.00. [15]

\section{Discussion}

In relation to the results of this research, the following discussions are held below:

Regarding the percentage of women who graduate in relation to the percentage of men, by academic semester of the Mechanical and Electrical Engineering degree of the National Technological University of South Lima, which is equal to $8.1 \%$; This result is similar to the research carried out at the Universidad de los Andes, points out that the world percentage of women graduated from the engineering area represents $7 \%$; This is because currently still the inequality and stereotypes that still prevails in these areas, this discourages women in the decision to pursue engineering careers. [16] Likewise, in Peru, only 25\% of students in Engineering careers are women, according to SUNEDU, and of this percentage, less than 5\% opt for specialties called "hard", such as Mechanical Engineering, Electronics, Civil or Mining. The gender gap in science, technology and innovation careers, which is a worldwide trend, is the result of discrimination against women in these areas of study. [17]

In relation to the academic performance of women in the professional career of Mechanical and Electrical Engineering, which is 12.98 , this represents a high average for the career; This result is similar to the research carried out in Spain, which indicates that $13.5 \%$ of women obtain the highest qualification compared to $10.1 \%$ of men [18]; In spite of this, there is still inequality in remuneration, and in companies there is a higher rate of hiring of male engineers. There is another fact that reaffirms the best performance of women. In the UTN of Buenos Aires when the best averages are analyzed, $50 \%$ are of the girls, this because they have more dedication, perseverance and responsibility. [19]

Regarding the high relationship that exists between the weighted average by specialty (Mechanics Subjects or Electrical Subjects) with the field of labor action where the women currently graduated from the career work; This result is similar to the research carried out at ECLAC in Santiago, Chile, where it is pointed out that the results of this study confirm that academic performance is a necessary condition for a successful insertion in the labor field. [20]

\section{Conclusions}

It is concluded that the percentage of women who graduate in relation to the percentage of men, by academic semester 2012-II to 2018-II of the career of Mechanical and Electrical Engineering of the National Technological University of South Lima, is equal to $8.1 \%$.

It is concluded that the weighted average of the academic performance of women graduated in the professional career of Mechanical and Electrical Engineering, is 12.98, this represents a high average for the career; so it can be indicated that the 38 women graduated from the Mechanical and Electrical Engineering career have had a good academic performance.

It is concluded that there is a significant high ratio of 0.822 between the weighted average by specialty with the field of labor action; These results agree with what has been pointed out in relation to the fact that there is a higher qualification in the 
specialty of Mechanics (AM) with an average range of 11.73 to 15.42 , and according to professional practice reports, of the 38 women graduated from The career of Mechanical and Electrical Engineering, 25 are developing in the field of specialty of Mechanics.

\section{Conflict of Interest}

The authors declare no conflict of interest.

\section{Acknowledgment}

The authors wish to recognize and thank the National Technological University of Lima South Lima for their support of this investigation.

\section{References}

[1] Tobal, S. Factors that influence the decision of engineering choice as a career in women. Latin American University of Science and Technology, 1-35. (2016).

[2] Panaia, M. The inclusion of women in the engineering profession. In: Virajes Magazine, Vol. 16, No. 1. Manizales: University of Caldas. 19-43 (2016).

[3] Sardina, M. Women and Engineering. Gender influence in career choice. University of cantabria. España. (2017).

[4] Gutiérrez, S. \& Duarte, M. Engineers or engineers: how women are conceived in the engineering field. Autonomous University of Baja California. 89-97 (2017).

[5] Martínez, K. Professions have sex. Men and women in female and male professions, the case of nurses and electrical mechanical engineers. University of San Luis. San Luis Potosi (2016).

[6] Berlien, V.; Variela, P. \& Robayo, C. I study national reality in training and promotion of women scientists in science, technology, engineering and mathematics. Ministry of Education. Chile (2017).

[7] Avolio, B.; Chávez, J.; Vílchez, C. \& Pezo, G. Factores que influyen en el ingreso, participación y desarrollo de las mujeres en carreras vinculadas a la ciencia, tecnología e innovación. Pontificia Universidad Católica del Perú (2018)

[8] Vega, D. Women in Electrical Mechanical Engineering. University of Piura. UDEP. 102-110 (2017).

[9] Marsh, V. (2017). Stereotypes affect the academic performance of women. Journal of Science, Technology, Society and Culture, 85-93.

[10] Castro, M. The research project and its elaboration scheme. Caracas: Uyapal. (2017).

[11] Hernández, R. Investigation Methodology Mexico: Mcgraw Hill (2018).

[12] Arias, F. Research project Caracas: Episteme (2016).

[13] Pedroza, H. \& Dicovskyi, L. Statistical Analysis System with SPSS. Nicaragua. INTA (2016).

[14] Rodríguez, M. Association Coefficients Mexico: Plaza and Valdez (2016).

[15] Ramos, R. Development and validation of instruments. University of Granada. Melilla (2017).

[16] Cárdenas, M., Eagly, A., Salgado, E., Goode, W., Heller, L., Jauregui, K., Galarza Quirós, N., Gormaz, N., Bunse, S., Godoy , M., Rocha Sánchez, T., Navarro, M., Sosa, F., Aguilera, Y., Schulmeyer, M., Tanure, B., Naranjo, M., Soto, B., Darre, S. and Tunqui, R. "Latin American female business executives: an interesting surprise", Gender in Management, Vol. 29 No. 1, pp. 2-24 (2014)

[17] Capital Peru: only $25 \%$ of women study engineering careers due to gender bias. Capital. Peru (2019).

[18] Álvarez. F.; Arias, A .; Serrallé, J. \& Varela, M. Choice of engineering studies: Influence of scientific education and gender stereotypes on student self-esteem. Journal of Research in Education, No. 12 (1), pp. 54-72 (2016).

[19] Braginsk, R. A key profession for the future of the country. Austral University. Clarion (2019).

[20] Garbanzo, G. Factors associated with academic performance in university students, a reflection from the quality of public higher education. Education Magazine, 31 (1) (2007). 